\title{
Bridging the Gap From Caldera Unrest to Resurgence
}

\author{
Valerio Acocella* \\ Dipartimento di Scienze, Università Roma Tre, Rome, Italy
}

Calderas often inflate up to a few meters for weeks to years, which is evidence of short-term unrest. Some calderas also show larger uplift (up to a thousand meters), achieved over the long-term (hundreds to thousands of years), manifest by a resurgent dome or block. How the short-term inflation relates to long-term resurgence is still poorly understood, even though established views consider the two processes distinct. This study exploits the longer deformation time series now available for several calderas, as well as the better understanding of magmatic processes and their evolution, to try to bridge the gap between these two scales of uplift. Available data challenge established views, suggesting that resurgence, rather than being produced by constant or continuous uplift, is the net cumulated result of tens to thousands distinct episodes of inflation, even interrupted by deflation episodes, as observed on short-term unrest.

Edited by:

Zhong Lu,

Southern Methodist University,

United States

Reviewed by:

Paul Randall Lundgren,

NASA Jet Propulsion Laboratory

(JPL), United States

Jorge Vazquez,

United States Geological Survey,

United States

John Stix,

McGill University, Canada

*Correspondence:

Valerio Acocella

acocella@uniroma3.it

Specialty section:

This article was submitted to

Volcanology,

a section of the journal

Frontiers in Earth Science

Received: 19 April 2019

Accepted: 19 June 2019

Published: 18 July 2019

Citation:

Acocella V (2019) Bridging the Gap From Caldera Unrest

to Resurgence.

Front. Earth Sci. 7:173.

doi: 10.3389/feart.2019.00173
These inflation episodes are ascribed to distinct pulses of shallow magma emplacement, with most of the magma remaining intruded, especially in felsic calderas. This supports an incremental growth of magmatic systems, consistently with that observed below resurgent calderas and what is inferred for plutons. Comparing the uplift (as expression of the intrusive record) and eruptive histories or resurgent calderas opens new exciting research paths to understand the causal relationships between intruded and erupted magma at a given caldera, thus enhancing its long-term eruptive forecast.

Keywords: caldera, unrest, resurgence, intrusion, deformation

\section{INTRODUCTION}

Calderas are the surface expression of large and long-lived (up to a few Ma) magmatic systems, produced by the repeated shallow accumulation of magma (Branney and Acocella, 2015). A distinct feature is their frequent state of unrest (Newhall and Dzurisin, 1988), systematically shown at all the monitored calderas from 1988 to 2014 (Acocella et al., 2015). Unrest is defined as a deviation of seismicity, deformation, gas emission, and/or other geophysical and geochemical indicators from normal baselines(s) to elevated activity, increasing the probability of eruption. Unrest is usually interpreted as resulting from shallow magma emplacement, even though the pressurization of any hydrothermal system or any remote triggering of far-field (regional) earthquakes may also contribute (Newhall and Dzurisin, 1988). Whatever the nature, many unrest episodes at calderas do not culminate in eruptions, this being a distinctive feature compared to other types of volcanoes (Phillipson et al., 2013; Acocella et al., 2015).

Unrest at calderas may last from weeks to years or decades, with some calderas (Yellowstone, Wyoming; Kilauea, Hawaii; Campi Flegrei, Italy; and Aira, Japan) being restless for a hundred years (Dvorak and Dzurisin, 1997). Among the various parameters highlighting unrest, deformation is widely used, as it can be easily detected, also remotely (as from space), its rate can be 
easily quantified, and its spatial extent promptly visualized. Most unrest episodes at calderas are characterized by inflation of $\mathrm{cm} / \mathrm{yr}$, even though rates may reach $\mathrm{m} / \mathrm{yr}$. A few calderas also experience deflation, as observed at Askja (Iceland) or Aso (Japan). Over decades to centuries, calderas experience several unrest episodes, with variable deformation pattern, given by repeated episodes of inflation, deflation, or stasis, largely regardless of any eruption (Newhall and Dzurisin, 1988; Acocella et al., 2015). However, some calderas also show more regular patterns, as continuous subsidence or uplift, the latter interrupted only by co-eruptive deflation (as Fernandina, Galapagos, or Axial Seamount, Juan de Fuca Ridge; Bagnardi and Amelung, 2012; Wilcock et al., 2016).

Some calderas, mainly those with a felsic magma composition, show a stronger and longer-term uplift, highlighting resurgence. Resurgence consists of the uplift of up to $\sim 1 \mathrm{~km}$ of the caldera floor over hundreds to thousands of years (Galetto et al., 2017, and references therein). The duration and uplift rate of resurgence are usually poorly constrained, being at best geologically inferred with a total amount of uplift over a given estimated period (often tens of thousands of years), which may be longer than that of effective uplift. In a very few resurgent calderas (Campi Flegrei; Toba, Sumatra; Siwi, Vanuatu; and IwoJima, Japan) more detailed information on the evolution of the vertical deformation highlights discontinuous phases of uplift, even alternated with subsidence episodes (Chen et al., 1995; De Silva et al., 2015; Marturano et al., 2018).

Therefore, available monitoring data allow quantification of shorter-term inflation episodes, representing specific incremental events during the life of a caldera, while geological data allow detection of a longer-term uplift, or resurgence. However, bridging the gap between these shorter-and longer-term uplifts, that means also finding any relationship between their responsible processes, is not straightforward and has often puzzled the volcanological community (e.g., Galetto et al., 2017, and references therein). In fact, resurgence has been often assumed to result from a continuous, even though not necessarily constant, uplift, related to a single or continuous supply of magma (e.g., Marsh, 1984; Kennedy et al., 2012; De Silva et al., 2015). How does this possibility reconcile with the much more discontinuous short-term behavior, characterized even by deflation, observed at several calderas in the last decades? Do we have to consider resurgence as a unique process which can be directly observed only at any presently continuously inflating caldera, detached in mechanisms, scales and variables from unrest (De Silva et al., 2015)? Or, conversely, do we have to consider resurgence as related to the more commonly observed complex behavior (including inflation, stasis and deflation) currently shown by restless resurgent calderas?

Here the possible relations between caldera inflation and resurgence are considered, in to propose an original working hypothesis trying to explain how magma emplaces below calderas. This working hypothesis benefits from both the increase in knowledge on the evolution of resurgent calderas, as well as from the longer monitoring time-series available on restless calderas, at times significantly enlarged by geological or archeological evidence (e.g., Newhall and Dzurisin, 1988; Chen et al., 1995; Di Vito et al., 2016).

\section{VERTICAL DISPLACEMENT AT RESURGENT CALDERAS}

In order to relate the shorter-term deformation behavior of resurgent calderas to their longer-term one, here I review available data.

As far as the shorter-term is concerned, active resurgent calderas often experience unrest, accompanied with vertical deformation; an overview is given in Newhall and Dzurisin (1988) and Acocella et al. (2015). Here I briefly describe all the monitored cases of resurgent calderas experiencing unrest, considering: (a) the availability of sufficiently long deformation time series; (b) the caldera composition (felsic or mafic). As for long-lasting time series, a few resurgent calderas (Campi Flegrei and Yellowstone) have been monitored for nearly a century and thus provide ideal cases. However, for a few other calderas, high resolution deformation time series spanning the last two or three decades are also available, providing a shorter but still valuable dataset. These resurgent calderas are felsic (Ischia, Italy; Long Valley, California; and Iwo Jima, Japan; Hill, 2006; Manzo et al., 2006; Ukawa et al., 2006; Ueda et al., 2018) or mafic (Sierra Negra and Alcedo; Galapagos) (Galetto et al., 2019, and references therein).

The deformation history of all the resurgent calderas satisfying points (a) and (b) is shown in Figure $\mathbf{1}$ and described below. The recent deformation on the top of the Campi Flegrei resurgent dome displays both major (rates of $\mathrm{m} / \mathrm{yr}$, as in the ' $80 \mathrm{~s}$ ) and minor (rates of $\mathrm{cm} / \mathrm{yr}$, as presently observed) episodes of inflation (Figure 1A; Acocella et al., 2015); these are interrupted by periods without deformation, or with subsidence. Such a behavior is qualitatively very similar to the one reconstructed in the last $2 \mathrm{ka}$, with several uplift, stasis and subsidence periods (Di Vito et al., 2016). A similar behavior, even though with less deformation, is shown by Yellowstone. Here the Sour Creek resurgent dome has been showing, in the last century, minor episodes (rates of $\mathrm{cm} / \mathrm{yr}$ ) of alternated uplift and subsidence (Figure 1B; Chang et al., 2007). On a shorter time span, in the last decades the northern, previously most uplifted portion of the resurgent block at Ischia has been experiencing continuous and constant subsidence (Figure 1C; Manzo et al., 2006), suggesting the ending of resurgence (Selva et al., 2019). Also in the last decades, Long Valley caldera underwent an overall uplift, even though accompanied with smaller periods of stasis, or minor subsidence (Figure 1D; Hill, 2006). In a very similar fashion, from the late '70s Iwo-Jima underwent episodic uplift, accompanied with periods of stasis or minor subsidence (Figure 1E; Ueda et al., 2018). As for mafic resurgent calderas, Sierra Negra has been showing, on a slightly shorter time-span, episodes of major and minor uplift, also separated by sudden sin-eruptive subsidence (Figure 1F; Chadwick et al., 2006). Finally, the mafic Alcedo caldera has been showing episodes of minor uplift and subsidence, the most recent of the latter due to the lateral migration of a sill formed by the previously emplaced magma (Figure 1G; Bagnardi, 2014).

In summary, the deformation curves of these resurgent calderas are all consistent with a complex behavior given by periods with variable duration of major or minor deformation 


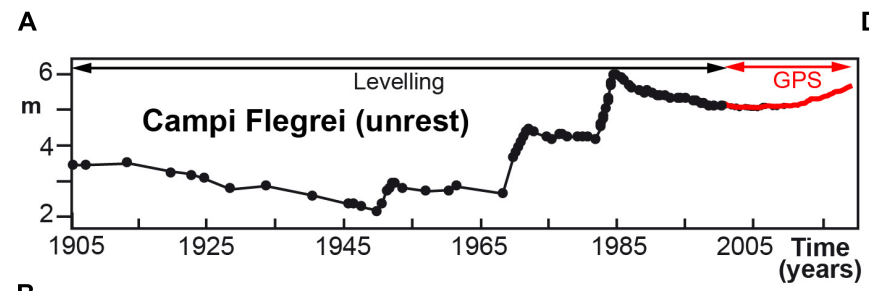

B
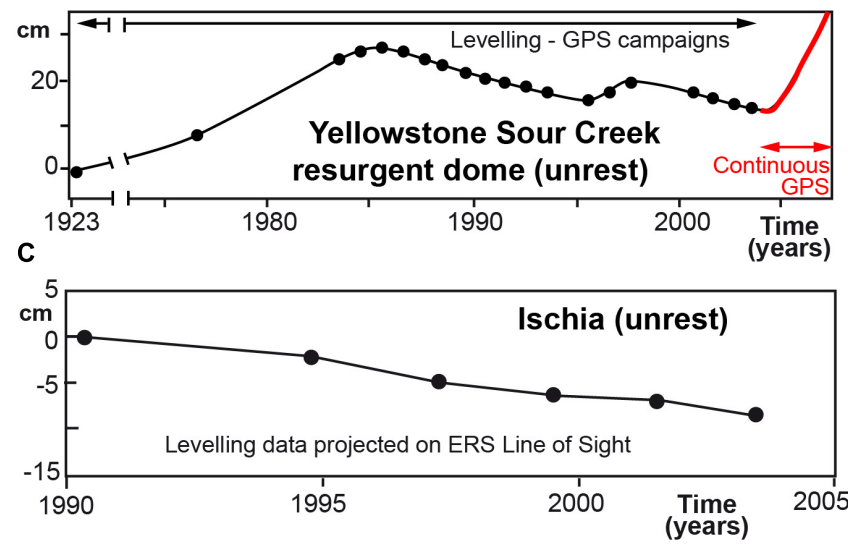

F
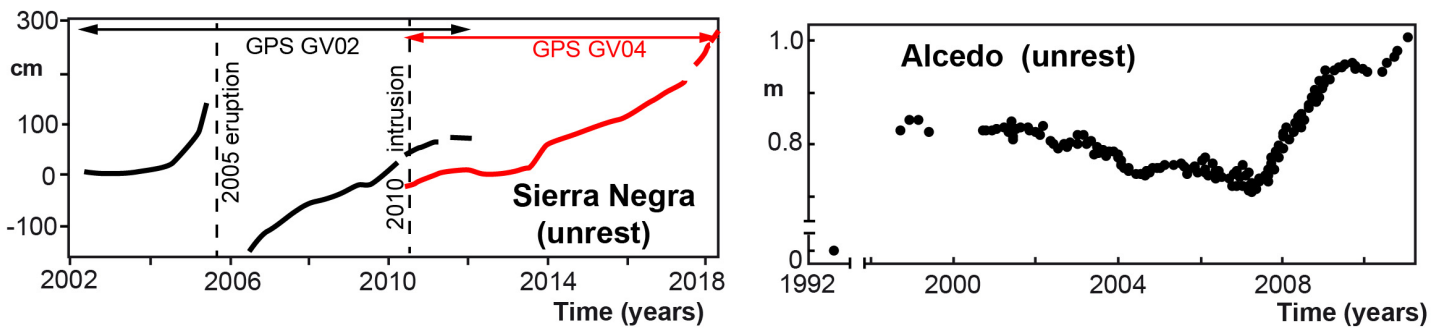

H
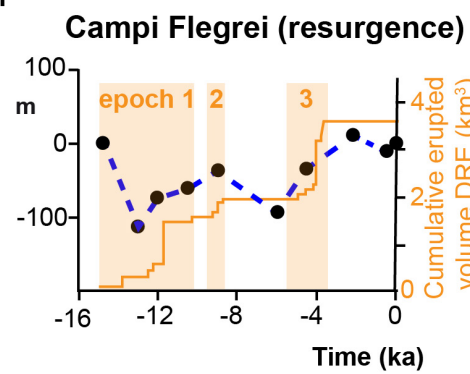

I
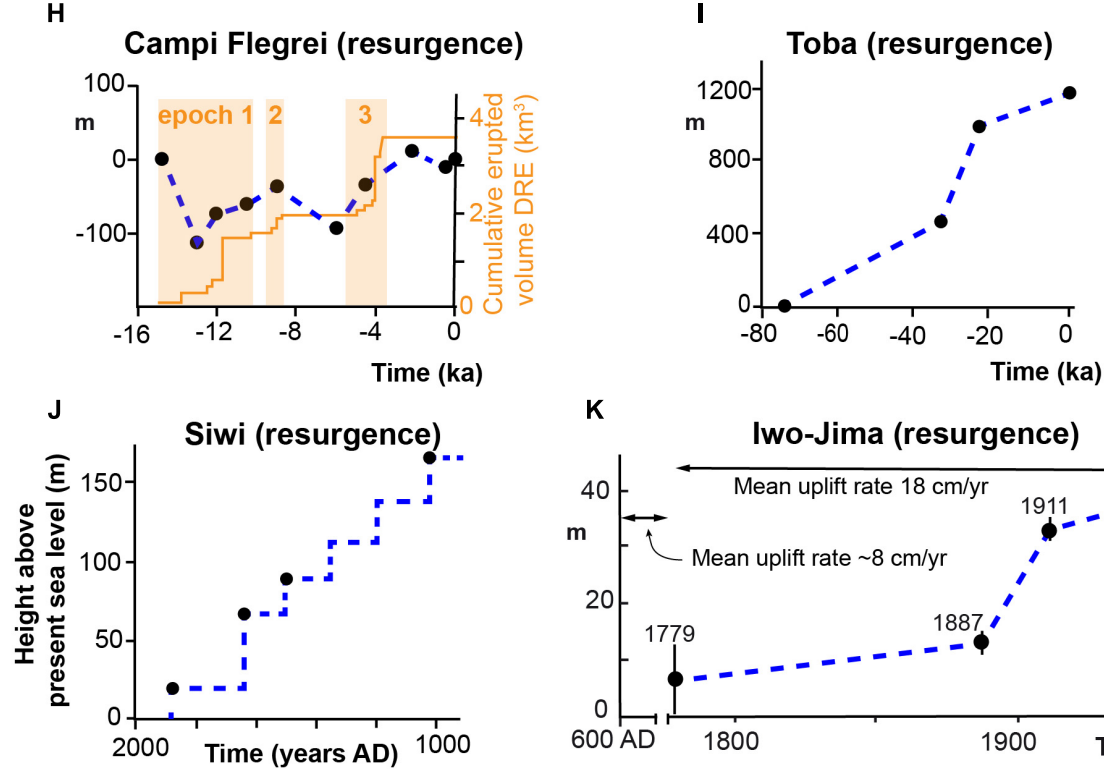

K

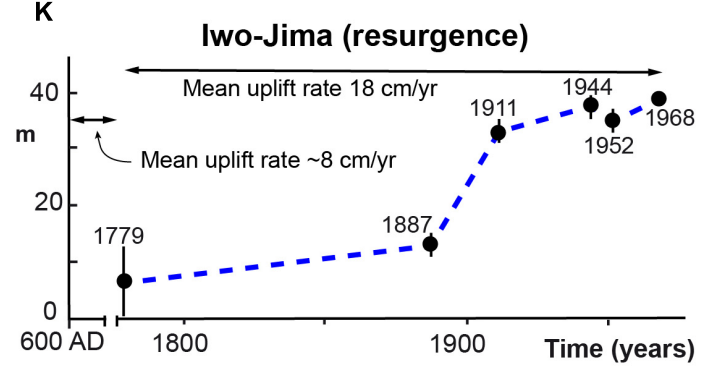

FIGURE 1 | Available curves of vertical deformation (specified on the $Y$-axis if in $\mathrm{m}$ or $\mathrm{cm}$; except case j) through time during unrest episodes or resurgence at several calderas. (A-G) short-term vertical displacement of monitored felsic (A-E) and mafic (F,G) resurgent calderas experiencing unrest. (H-K) Available curves of variation in the long-term vertical displacement of felsic resurgent calderas; in the Campi Flegrei case (H) the eruptive periods (orange bands) and cumulative erupted products (orange curve) are included. See text for references. 
(incremental behavior) responsible for an overall net uplift, even though subsidence episodes occur as a consequence of degassing, lateral magma transfer, or eruptions; in particular, below resurgent calderas lateral magma transfer, preferably through sills, is important to move mafic and, possibly, felsic magma outside the less permeable region of resurgence, eventually feeding distal eruptions (e.g., Galetto et al., 2017; Kennedy et al., 2018). In all the cases of Figure 1, the most important uplift episodes have been systematically interpreted as resulting from the shallow emplacement of mafic or felsic magma (Chadwick et al., 2006; Dzurisin et al., 2012; Amoruso et al., 2014; D’Auria et al., 2015; Galetto et al., 2019), suggesting a similarity with the causes leading to their longer-term resurgence.

Obtaining information on the evolution of the longer-term deformation of resurgent calderas is more challenging and, so far, the only known cases are Iwo-Jima, Campi Flegrei, Toba and Siwi (Newhall and Dzurisin, 1988, and references therein; Chen et al., 1995; De Silva et al., 2015; Marturano et al., 2018). These resurgences are characterized by very different durations (from $<1$ to $70 \mathrm{ka}$ ) and frequency of the measures constraining the vertical deformation (black dots in the diagrams; from hundreds of years to tens of thousands of years). The resurgent dome of Campi Flegrei shows uplift alternated with subsidence. While net uplift dominates, the temporary subsidence may be still significant at times, on the order of several tens of $\mathrm{m}$ (Figure 1H; Marturano et al., 2018). In addition, eruptive activity has been quite continuous and with similar rates after the last caldera forming eruption at $15 \mathrm{ka}$ (Figure 1H; Smith et al., 2011), implying that here caldera formation did not significantly affect the rate of volcanism. Toba shows an apparently continuous, albeit not constant, uplift (Figure 1I; De Silva et al., 2015). As this curve has been built on only four measurements, one cannot exclude that any period of no deformation, or even subsidence (as observed for Campi Flegrei), occurred in between. A similar behavior is shown by Siwi and Iwo-Jima, where the available points describe incremental uplift phases interrupted by stases (Figures 1J,K; Chen et al., 1995) and minor subsidence (Figure 1K; Newhall and Dzurisin, 1988). Again, the frequency of the available points does not allow one to exclude the existence of any interruption in the uplift further marked by subsidence.

\section{BRIDGING THE GAP}

On the short-term, the considered resurgent calderas show that unrest is characterized by uplift and subsidence periods, with the former dominating and indicating net uplift, independently of the caldera composition. On the long-term, the evolution of resurgence also appears dominated by net uplift, with subsidence episodes detected in two cases (Campi Flegrei and Iwo-Jima) and stases in two cases (Toba and Siwi); the identification of any subsidence episode at Toba and Siwi may be hindered by the poor frequency of the available measurements. However, as all the investigated active resurgences on the shorter-term systematically include stasis or subsidence periods between episodes of uplift, also on time spans of up to $2 \mathrm{ka}$ (Campi Flegrei), it is reasonable to assume that resurgence may also follow a similar behavior, with uplift being frequently interrupted by stasis or subsidence episodes. Indeed, the currently observed unrest episodes should be considered as instantaneous frames of a much longer process, where only the cumulative effect may be known.

Overall, these data suggest that resurgence is not the result of a constant, and not even continuous, uplift process detached from unrest (Figures 2A,B). Rather, the vertical deformation during resurgence should be seen as a sequence of different episodes of uplift, repose, subsidence, each of very different duration, in which net uplift predominates on the longer-term (Figure 2C). Such a discontinuous uplift history also explains the apparent discrepancy between the inferred lower rates of uplift during resurgence and the measured higher rates during unrest (De Silva et al., 2015). Consistently with what is understood on the shorter-term (unrest), where caldera inflation commonly results from magma emplacement, each uplift episode during resurgence should be interpreted as due to an episode of magma intrusion, relaxing the importance of any hydrothermal contribute.

This new perspective on the development of resurgence has several implications.

First, resurgence should be interpreted as resulting from a complex evolution of a magmatic system, in which repeated episodes of shallow magma emplacement responsible for uplift predominate over possible episodes of subsidence. In fact, each episode of intrusion may be followed by a stage of lateral propagation (testified by subsidence in the caldera center; Kennedy et al., 2018), quiescence (testified by a stasis in the deformation), degassing and crystallization (both testified by continuous subsidence), eruption (testified by abrupt subsidence), or a new episode of intrusion (testified by a different uplift rate) (Figure 2C). This supports an overall incremental growth of the magmatic system, consistently with what observed below eroded resurgent calderas or through drillholes, where the shallow plumbing system consists of stacked sills/laccoliths inferred to have driven resurgence (Fridrich et al., 1991; McConnell et al., 1995; DuBray and Pallister, 1999; Kawakami et al., 2007; Kennedy et al., 2015; Hildreth et al., 2017). Such an incremental growth of the magmatic system during resurgence is also consistent with that inferred for large felsic volcanic fields (such as the Laguna del Maule, Chile; Singer et al., 2018) and for the growth of plutonic bodies (Glazner et al., 2004; De Saint Blanquat et al., 2011; Coleman et al., 2016), confirming that volcanic and plutonic processes may be characterized by similar rates (De Saint Blanquat et al., 2006). Likely, each episode of inflation would be characterized by the emplacement and growth of a tabular (sill-like) intrusion, which may eventually inflate and develop laccoliths, as commonly observed at exposed plutons or geophysically imaged/detected below volcanoes (e.g., Bai and Greenhalgh, 2005; Brown, 2013, and references therein). A magmatic system is not necessarily fed by the same intrusion rates or volumes: in fact, magma may emplace suddenly, with higher rates (major unrest episodes), or slowly, with a much smoother build-up (minor unrest episodes), and with very different volumes.

As a consequence of this complex evolution, the real duration of resurgence cannot be established based on the time frame given 


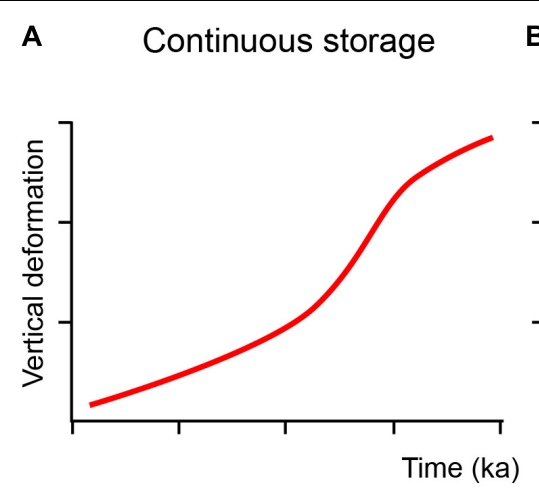

B
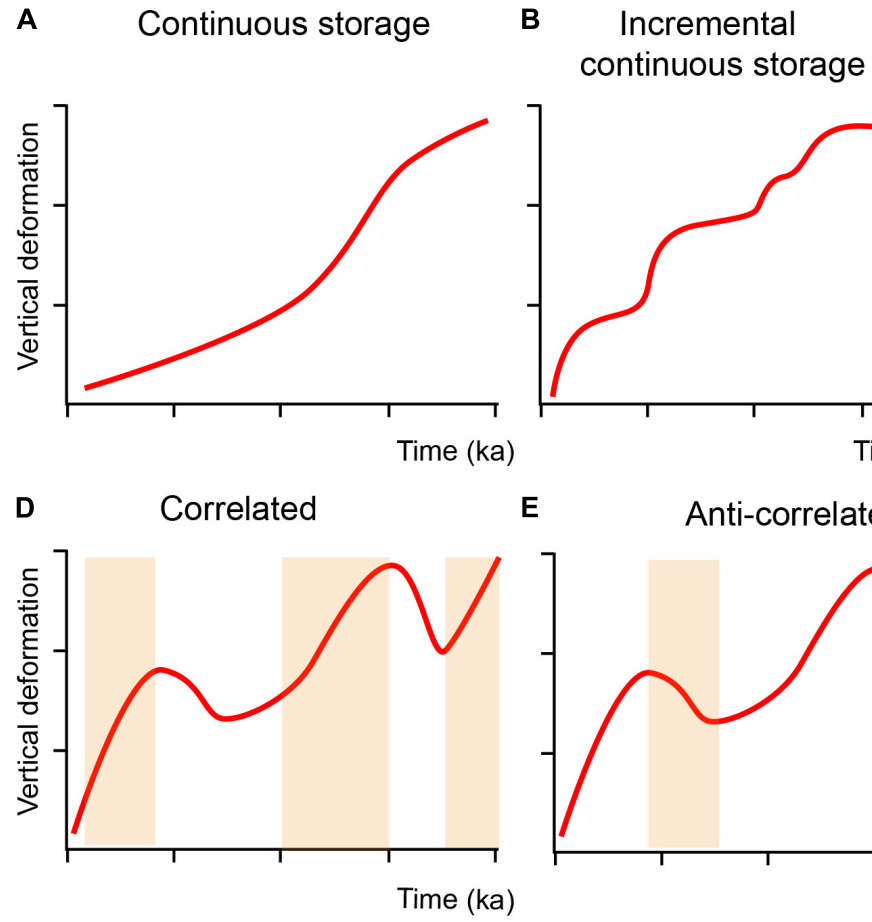

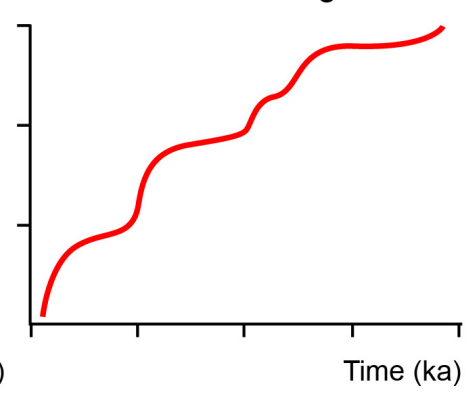

E

\section{Incremental discontinuous storage}

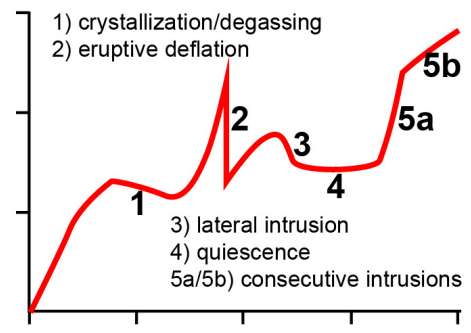

Time (ka)

$\mathbf{F}$

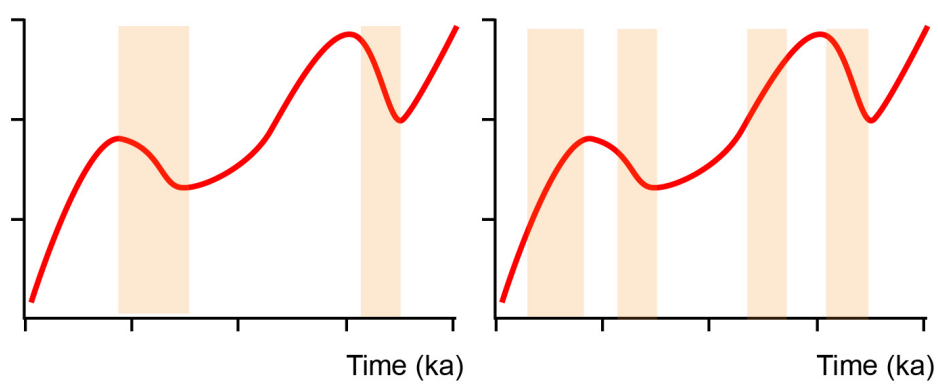

FIGURE 2 | (A-C) Possible evolutionary models for resurgence. The incremental discontinuous storage model is more consistent with available short-term monitoring data: here net uplift is interrupted by stasis (quiescence) or even subsidence, due to crystallization/degassing, eruptions or lateral intrusions. (D-E) Possible relationships between uplift (as resulting from magma intrusion) and eruptive activity (eruptive epochs are highlighted by orange bands) during resurgence. The case of Campi Flegrei (Figure 1H) highlights a correlation between magma intrusion and eruption; however, most resurgent calderas would show an anti-correlation, or simply a non-correlation (Galetto et al., 2017).

by the availability of monitoring data alone. A given resurgence may in fact be characterized by a decade- or century-long subsidence, without necessarily implying the ending of the resurgence process. Only geologic data referring to a much longer time frame may allow evaluating the prevalence of uplift or subsidence, and thus the duration of resurgence. This implies that resurgence may in principle last as long as the caldera experiences unrest with some net uplift, virtually until the magmatic system of the caldera remains active.

Second, the proposed perspective also has implications to define the capacity of volcanoes to store or erupt magma, with consequences in forecasting their longer-term eruptive hazard. This process is introduced by Figure $\mathbf{1 H}$, where the variations in the vertical deformation accompanying resurgence at Campi Flegrei are shown against the three post-caldera collapse eruptive epochs (orange bars) and, more importantly, against the cumulative erupted volumes (Smith et al., 2011 and references therein). The comparison shows a broad correlation between periods of resurgent uplift and volume of erupted products, suggesting that the magma responsible for uplift during resurgence was also partly erupted. However, Campi Flegrei shows an end-member type of resurgence, in which the intruded magma is usually able to reach the surface, erupting; this is testified by the fact that the volume of the resurgence is less than that of the erupted volume; a similar behavior is shown by Long Valley (Galetto et al., 2017). This feature is quite uncommon, as most resurgent calderas are characterized by resurgence volumes much higher than the erupted volumes, indicating that most of the intruded magma is not erupted: notable examples include Ischia and Valles (New Mexico; Galetto et al., 2017). Therefore, the relationship between the amount of uplift and erupted volumes observed at Campi Flegrei should not hold for most resurgent calderas. This feature is currently difficult to test in detail for other resurgent calderas, because of the general lack of information on the uplift rates during resurgence. Still, future research should be devoted at better defining and understanding the relationships between the magma intruded (as suggested by the uplift rates) and the magma erupted through time during resurgence. It is possible that a resurgent caldera behaves like Campi Flegrei (uplift periods coinciding with eruptive periods; Figure 2D) or, conversely, that the uplift is anti-correlated to eruptions (Figure 2E), indicating that the stored magma cannot be erupted (Galetto et al., 2017); intermediate behaviors, denoting non-correlations, may also occur (Figure 2F). Other conditions being similar (including the magmatic supply), it may be expected that an uplift correlated with eruptions is smaller than an anti-correlated one, because of the smaller amount of magma remaining intruded. A further problem to test is whether the correlation or anti-correlation between uplift and erupted volumes depend upon the composition of the intruded magma, with mafic magma being more easily erupted 
and thus promoting a correlated behavior (Figure 2D) and felsic magmas mainly promoting an anti-correlated behavior (Figure 2E). Whatever the specific pattern, defining the detailed time distribution of intruded and extruded volumes, as well as any causal relationship, at a specific resurgent caldera may open new exciting perspectives in forecasting eruptions on the long-term, once the recent intrusive history is reconstructed. This becomes particularly useful as the possibility to have an eruption may not only depend on the features of the ongoing unrest, but also on those of any previous unrest episode(s), which may have already loaded the system to its limit of storing magma (Acocella et al., 2015).

\section{CONCLUSION}

This overview challenges established views on resurgence, which consider it detached from unrest. Rather, available data suggest that resurgence results from the net uplift produced by repeated (tens to thousands) episodes of magma intrusions, similarly to those currently monitored at any resurgent caldera on a shorter-term. These repeated intrusions can be separated by quiescence or subsidence, the latter driven by magma crystallization, degassing, eruption or lateral intrusion. This perspective suggests an incremental growth of magma reservoirs,

\section{REFERENCES}

Acocella, V., Di Lorenzo, R., Newhall, C., and Scandone, R. (2015). An overview of recent (1988 to 2014) caldera unrest: knowledge and perspectives. Rev. Geophys. 53, 896-955. doi: 10.1002/2015RG000492

Amoruso, A., Crescentini, L., and Sabbetta, I. (2014). Paired deformation sources of the Campi Flegrei caldera (Italy) required by recent (1980-2010) deformation history. J. Geophys. Res. 119, 3276-3289.

Bagnardi, M. (2014). Dynamics of Magma Supply, Storage, and Migration at Basaltic Volcanoes: Geophysical Studies of the Galâpagos and Hawaiian Volcanoes. Ph.D Dissertation, University of Miami, Coral Gables.

Bagnardi, M., and Amelung, F. (2012). Space-geodetic evidence for multiple magma reservoirs and subvolcanic lateral intrusions at fernandina volcano, galápagos islands. J. Geophys. Res. 117:B10406. doi: 10.1029/2012JB009465

Bai, C., and Greenhalgh, S. (2005). 3D multi-step travel time tomography: imaging the local, deep velocity structure of rabaul volcano, papua new guinea. Phys. Earth Planet. Int. 151, 259-275. doi: 10.1016/j.pepi.2005.03.009

Branney, M., and Acocella, V. (2015). "Calderas," in The Encyclopaedia of Volcanoes, eds H. Sigurdsson, B. Houghton, H. Rymer, and J. Stix (Cambridge: Academic Press).

Brown, M. (2013). Granite: from genesis to emplacement. Geol. Soc. Am. Bull. 125, 1079-1113. doi: 10.1130/b30877.1

Chadwick, W. W., Geist, D. J., Jonsson, S., Poland, M., Johnson, D. J., and Meertens, C. M. (2006). A volcano bursting at the seams: inflation, faulting, and eruption at sierra negra volcano, galápagos. Geology 34, 1025-1028.

Chang, W. L., Smith, R. B., Wicks, C., Farrell, J. M., and Puskas, C. M. (2007). Accelerated uplift and magmatic intrusion of the yellowstone caldera, 2004 to 2006. Science 318, 952-956. doi: 10.1126/science.1146842

Chen, J. K., Taylor, F. W., Edwards, R. L., Cheng, H., and Burr, G. S. (1995). Recent emerged reef terraces of the yenkahe resurgent block, tanna, vanuatu: implications for volcanic, landslide and tsunami hazards. J. Geol. 103, 577-590. doi: $10.1086 / 629777$

Coleman, D. S., Mills, R. D., and Zimmerer, M. J. (2016). The pace of plutonism. Elements 12, 97-102. doi: 10.2113/gselements.12.2.97

D’Auria, L., Pepe, S., Castaldo, R., Giudicepietro, F., Macedonio, G., Ricciolino, P., et al. (2015). Magma injection beneath the urban area of naples: a new similar to what has been observed or drilled below resurgent calderas and what has been inferred for plutons, more complex than previously inferred. As the real duration of resurgence extends beyond any monitored period, it can be appreciated only with geologic data. This perspective opens new exciting paths for research, particularly trying to compare the uplift (as resulting from the intrusive record) and eruptive histories or resurgent calderas. This may allow understanding the causal relationships promoting magma eruption from a certain intruded budget at a given caldera, thus promoting long-term eruptive forecasts.

\section{AUTHOR CONTRIBUTIONS}

The author confirms being the sole contributor of this work and has approved it for publication.

\section{ACKNOWLEDGMENTS}

Federico Galetto and Marco Bagnardi provided helpful suggestions that improved the manuscript. Three reviewers provided helpful and constructive suggestions.

mechanism for the 2012-2013 volcanic unrest at campi flegrei caldera. Sci. Rep. 5:13100. doi: 10.1038/srep 13100

De Saint Blanquat, M., Habert, G., Horsman, E., Morgan, S. S., Tikoff, B., Pauneau, P., et al. (2006). Mechanisms and duration of non-tectonically assisted magma emplacement in the upper crust: the black mesa pluton, henry mountains, utah. Tectonophysics 428, 1-31. doi: 10.1016/j.tecto.2006. 07.014

De Saint Blanquat, M., Horsman, E., Habert, G., Morgan, S., Vanderhaeghe, O., Law, R., et al. (2011). Multiscale magmatic cyclicity, duration of pluton construction, and the paradoxical relationship between tectonism and plutonism in continental arcs. Tectonophysics 500, 20-33. doi: 10.1016/j.tecto. 2009.12.009

De Silva, S. L., Mucek, A. E., Gregg, P. M., and Pratomo, I. (2015). Resurgent toba - field, chronologic, and model constraints on duration, time scales and mechanisms of resurgence at large calderas. Front. Earth Sci. 3:25. doi: 10.3389/ feart.2015.00025

Di Vito, M. A., Acocella, V., Aiello, G., Barra, D., Battaglia, M., Carandente, A., et al. (2016). Magma transfer at campi flegrei caldera (Italy) before the last 1538 AD eruption. Sci. Rep. 6:32245. doi: 10.1038/srep32245

DuBray, E. A., and Pallister, J. S. (1999). Recrystallization and anatexis along the plutonic-volcanic contact of the turkey creek caldera. Arizona. Geol. Soc. Am. Bull. 111, 143-153. doi: 10.1130/0016-7606(1999)111<0143:raaatp >2.3.co;2

Dvorak, J. J., and Dzurisin, D. D. (1997). Volcano geodesy: the search for magma reservoirs and the formation of eruptive vents. Rev. Geophys. 35, 343-384. doi: 10.1126/sciadv.aat1513

Dzurisin, D., Wicks, C. W., and Poland, M. P. (2012). History of surface displacements at the yellowstone caldera, wyoming, from leveling surveys and InSAR observations, 1923-2008. U.S. Geol. Surv. Prof. Pap. 1788:68.

Fridrich, C. J., Smith, R. P., DeWitt, E. D., and McKee, E. H. (1991). Structural, eruptive, and intrusive evolution of the grizzly peak caldera, sawatch range, colorado. Geol. Soc. Am. Bull. 103, 1160-1177. doi: 10.1130/0016-7606(1991) $103<1160$ :seaieo $>2.3$. co; 2

Galetto, F., Acocella, V., and Caricchi, L. (2017). Caldera resurgence driven by magma viscosity contrasts. Nat. Commun. 8:1750. doi: 10.1038/s41467-017$01632-y$ 
Galetto, F., Bagnardi, M., Acocella, V., and Hooper, A. (2019). Noneruptive unrest at the caldera of alcedo volcano (Galápagos Islands) revealed by InSAR data and geodetic modelling. J. Geophys. Res. 124, 3365-3381. doi: 10.1029/ 2018JB017103

Glazner, A. F., Bartley, J. M., Coleman, D. S., Gray, W., and Taylor, L. Z. (2004). Are plutons assembled over millions of years by amalgamation from small magma chambers? GSA Today 14:4/5, doi: 10.1130/1052-5173

Hildreth, W., Fierstein, J., and Calvert, A. (2017). Early postcaldera rhyolite and structural resurgence at long valley caldera, california. J. Volcanol. Geotherm. Res. 335, 1-34. doi: 10.1016/j.jvolgeores.2017.01.005

Hill, D. P. (2006). Unrest in long valley caldera, california, 1978 - 2004. Geol. Soc. Spec. Pub. 269, 1-24.

Kawakami, Y., Hoshi, H., and Yamaguchi, Y. (2007). Mechanism of caldera collapse and resurgence: observations from the northern part of the kumano acidic rocks, kii peninsula, southwest Japan. J. Volcan. Geoth. Res. 167, 263-281. doi: 10.1016/j.jvolgeores.2007.02.003

Kennedy, B., Holohan, E. P., Stix, J., Gravley, D. M., Davidson, J. R. J., and Cole, J. W. (2018). Magma plumbing beneath collapse caldera volcanic systems. Earth Sci. Rev. 177, 404-424. doi: 10.1038/ncomms 12295

Kennedy, B., Stix, J., Hon, K., Deering, C., and Gelman, S. (2015). Magma storage, differentiation, and interaction at lake city caldera, colorado, USA. Geol. Soc. Am. Bull. 128, 764-776. doi: 10.1130/B31305.1

Kennedy, B., Wilcox, J., and Stix, J. (2012). Caldera resurgence during magma replenishment and rejuvenation at valles and lake city calderas. Bull. Volcanol. 74, 1833-1847. doi: 10.1007/s00445-012-0641-x

Manzo, M., Ricciardi, G. P., Casu, F., Ventura, G., Zeni, G., Borgstrom, S., et al. (2006). Surface deformation analysis in the Ischia Island (Italy) based on spaceborne radar interferometry. J. Volcanol. Geotherm. Res. 151, 399-416. doi: 10.1016/j.jvolgeores.2005.09.010

Marsh, B. D. (1984). On the mechanics of caldera resurgence. J. Geophys. Res. 89, 8245-8251. doi: 10.1002/9781118782095.ch4

Marturano, A., Isaia, R., Aiello, G., and Barra, D. (2018). Complex dome growth at campi flegrei caldera (Italy) in the last $15 \mathrm{ka}$. J. Geophys. Res. 123, 8180-8197. doi: $10.1029 / 2018 \mathrm{jb} 015672$

McConnell, V. S., Shearer, C. K., Eichelberger, J. C., Keskinen, M. J., Layer, P. W., and Papike, J. J. (1995). Rhyolite intrusions in the intracaldera bishop tuff, long valley caldera, california. J. Volcanol. Geotherm. Res. 67, 42-60.
Newhall, C. G., and Dzurisin, D. (1988). Historical Unrest at Large Calderas of the World. US Geol. Surv. Bull. 1855, 210-213.

Phillipson, G., Sobradelo, R., and Gottsmann, J. (2013). Global volcanic unrest in the 21st century: an analysis of the first decade. J. Volcanol. Geotherm. Res. 264, 183-196. doi: 10.1016/j.jvolgeores.2013.08.004

Selva, J., Acocella, V., Bisson, M., Costa, A., Caliro, S., De Martino, P., et al. (2019). Volcanic and related hazards at Ischia (Italy): state of knowledge and future perspectives. J. Appl. Volcanol. 21, EGU2019-EGU18967.

Singer, B. S., Le Mével, H., Licciardi, J. M., Córdova, L., Tikoff, B., Garibaldi, N., et al. (2018). Geomorphic expression of rapid holocene silicic magma reservoir growth beneath laguna del maule. Chile. Sci. Adv. 4:eaat1513. doi: 10.1126/ sciadv.aat1513

Smith, V. C., Isaia, R., and Pearce, N. J. G. (2011). Tephrostratigraphy and glass compositions of post-15 kyr campi flegrei eruptions: implications for eruption history and chronostratigraphic markers. Quat. Sci. Rev. 30, 3638-3660. doi: 10.1016/j.quascirev.2011.07.012

Ueda, H., Nagai, M., and Tanada, T. (2018). Phreatic eruptions and deformation of Ioto Island (Iwo-jima), Japan, triggered by deep magma injection. Earth Planet. Space 70:38.

Ukawa, M., Fujita, E., Ueda, H., Kumagai, T., Nakajima, H., and Morita, H. (2006). Long-term geodetic measurements of large scale deformation at IwoJima caldera, Japan. J. Volcanol. Geotherm. Res. 150, 98-118. doi: 10.1016/j. jvolgeores.2005.07.008

Wilcock, W. S. D., Tolstoy, M., Waldhauser, F., Garcia, C., Tan, Y. J., Bohnenstiehl, D. R., et al. (2016). Seismic constraints on caldera dynamics from the 2015 axial seamount eruption. Science 354, 1395-1399. doi: 10.1126/science.aah5563

Conflict of Interest Statement: The author declares that the research was conducted in the absence of any commercial or financial relationships that could be construed as a potential conflict of interest.

Copyright (c) 2019 Acocella. This is an open-access article distributed under the terms of the Creative Commons Attribution License (CC BY). The use, distribution or reproduction in other forums is permitted, provided the original author(s) and the copyright owner(s) are credited and that the original publication in this journal is cited, in accordance with accepted academic practice. No use, distribution or reproduction is permitted which does not comply with these terms. 